\title{
Intraoperative factors affecting the postoperative core body temperature in general surgery
}

\author{
Chalari E. Intas G., Katsimpra D., Kaiva K., Palgimezi A., Panoutsopoulos G. \\ General Hospital Nikaia 'Agios Panteleimon', Dept of Anaesthesiology, Athens, Greece
}

Differences in intraoperative factors between patients with hypothermia and normothermia

\begin{tabular}{|l|c|c|c|}
\hline & Hypothermia & Normothermia & p \\
\hline Duration of operation (min) & $118.6 \pm 47.8$ & $127.7 \pm 64.8$ & 0.016 \\
\hline Heart rates & $69.3 \pm 10.7$ & $73.2 \pm 16.9$ & 0.020 \\
\hline Midazolame & $29(40.8 \%)$ & $15(31.3 \%)$ & 0.049 \\
\hline Propofol & $50(70.4 \%)$ & $39(8.3 \%)$ & 0.004 \\
\hline Local anesthetics & $20(28.2 \%)$ & $9(18.7 \%)$ & 0.012 \\
\hline Sugammadex & $17(23.9 \%)$ & $7(14.6 \%)$ & 0.008 \\
\hline Atropine & $1(1.4 \%)$ & $5(10.4 \%)$ & 0 \\
\hline Position of anaesthesia (trendelnburg) & $4(5.6 \%)$ & $6(12.5 \%)$ & 0.049 \\
\hline Site of anaesthesia (subarachnoid) & $14(19.7 \%)$ & $4(8.5 \%)$ & 0.005 \\
\hline Glucose levels & $114.2 \pm 55.5$ & $104.8 \pm 19.9$ & 0.002 \\
\hline Creatinine levels & $1.19 \pm 1.47$ & $0.87 \pm 0.16$ & 0.028 \\
\hline
\end{tabular}

Background: The intraoperative hypothermia is associated with the drugs administered during anesthesia, the potential exposure to cold air currents into the operating room, the fluids (including blood) which are administered at a normal room temperature and the increased heat loss to the external environment due to the incisional or even the exposure of patient's organs in the external environment. The intraoperative hypothermia often leads to postoperative hypothermia in ICU or in the post-anesthetic care unit (PACU), with a rate of $60 \%$.

Goal of Study: The goal of the study was the investigation of intraoperative factors that affects the postoperative core body temperature in PACU.

Materials and methods: This was a prospective, randomized and controlled clinical trial conducted in a large general hospital of Athens, Greece. The sample of the study consisted of 119 patients who underwent different type of surgeries. Hypothermia was defined when the tympanic temperature of patients was under $36^{\circ} \mathrm{C}$. The temperature of patients was measured at the middle of the surgery (intraoperative), at the admission in the PACU and before the discharge of the PACU. The statistical analysis of the results was performed by $\mathrm{x}^{2}$ test and Student $t$ test using the statistical package SPSS for Windows (version 21) and the statistical significance was set to $p=0.05$.

Results: Hypothermia rate of patients when admitted in PACU was $71.4 \%$. Factors affecting the hypothermia (vs normothermia) rate in PACU were female gender (54.1 vs $29.4 \%, \mathrm{p}=0.001$ ), low weight $(79.7 \pm 15.3$ vs $81.2 \pm 23.7 \mathrm{~kg}, \mathrm{p}=0.006)$, prolonged surgery $(130.9 \pm 64.9$ vs $120.2 \pm 52.3 \mathrm{~min}, \mathrm{p}=0.026)$, and the subarachnoid anaesthetic technique ( 18.9 vs $6 \%, \mathrm{p}=0.045$ ). The hypothermia on discharge from PACU was affected by female gender ( 54.2 vs $36.1 \%$, p=0.006), low weight $(79.6 \pm 15.7$ vs $81.5 \pm 23.1 \mathrm{~kg}, \mathrm{p}=0.024)$, severity of surgery $(77.1$ vs $63.9 \%, p=0.008)$, prolonged surgery $(138.3 \pm 62.8$ vs $114.8 \pm 50.6$ min, $\mathrm{p}=0.028)$, propofol (74.7 vs $86.1 \%, \mathrm{p}=0.001)$, sugammadex $(20.5$ vs $30.6 \%, \mathrm{p}=0.001$ ), muscle relaxants (71.1 vs $80.6 \%, \mathrm{p}=0.001$ ), whether the patient was intubated or not during surgery (69.9 vs $76.5 \%, \mathrm{p}=0.001)$, subarachnoid anaesthetic technique (18.1 vs $5.6 \%$, $\mathrm{p}=0.001$ ) and systolic blood pressure on discharge from PACU $(130.7 \pm 22.9$ vs $123.7 \pm 15.3 \mathrm{mmHg}, \mathrm{p}=0.024)$.

\section{References}

Karalapillai D, Story D. Hypothermia on arrival in the intensive care unit after surgery. Crit Care Resusc. 2008;10(2):116-119.

Kim EJ, Yoon H. Preoperative factors affecting the intraoperative core body temperature in abdominal surgery under general anesthesia: an observational cohort. Clin Nurse Spec. 2014;28(5):268-76.

Kasai T, et al. Preoperative blood pressure and catecholamines related to hypothermia during general anesthesia. Acta Anaesthesiol Scand. 2003;47(2):208-212.

Copyright (C) 2016. Chalari E. Intas G., Katsimpra D., Kaiva K., Palgimezi A., Panoutsopoulos G. Email: jeniferaki2@gmail.com 